\title{
Análise comparativa da higienização da alface crespa (Lactuca sativa L.) utilizando sanitizante à base de ácido lático e à base de cloro
}

\section{Comparative analysis of green-leaf lettuce (Lactuca sativa L.) sanitation using lactic acid-based and chlorine-based sanitizer}

\author{
1 Francisca Geane de Lima Teixeira \\ 2 Renata Carmo de Assis renata.carmo.assis@gmail.com \\ 3 Lúcia Mara dos Reis Lemos
}

\footnotetext{
1 Especialista em Vigilância Sanitária dos Alimentos. Tecnóloga dos Alimentos. Universidade Estadual do Ceará. Mestre em Nutrição e Saúde. Espacialista em Gestão da Qualidade em Serviço de Alimentação.

Mestre em Tecnologia em Alimentos. Especialista em Nutrição Clinica e Esportiva. Graduada em Tecnologia em Alimentos. Universidade Estadual do Ceará
}

\section{Resumo}

Os vegetais são potenciais veiculadores de microrganismos que podem estar associados às Doenças Transmitidas por Alimentos. A fim de se evitar problemas de contaminação microbiana, os sanitizantes são utilizados durante o seu processamento. 0 objetivo deste trabalho foi realizar uma análise comparativa da higienização da alface crespa (Lactuca sativa L.) utilizando-se sanitizante à base de cloro e à base de ácido lático em uma cozinha industrial no Ceará. Para avaliar o processamento da alface, foi aplicada uma lista de verificação baseada na RDC 216/2004, como também realizadas análises microbiológicas (Coliformes termotolerantes e Salmonella sp.) nas amostras submetidas aos diferentes tratamentos. Os índices de conformidade nos blocos avaliados na lista de verificação foi de $96,3 \%$. Os resultados microbiológicos apresentaram ausência de Salmonella sp. e os tratamentos com sanitizantes à base de cloro e ácido lático apresentaram conformidades para coliformes. 0 uso do sanitizante à base de ácido lático mostrou-se tão eficiente quanto os sanotizantes à base de cloro.

Palavras-chave:

Microbiologia. Sanitização. Vegetais.

\begin{abstract}
Vegetables are potential carriers of microorganisms that may be associated with Foodborne Diseases. In order to avoid microbial contamination problems, sanitizers are used during its processing. The objective of this study was to perform a comparative analysis of the sanitization of green-leaf lettuce (Lactuca sativa L.) using chlorine-based and lactic acid-based sanitizer in an industrial kitchen in Ceará. To evaluate the processing of lettuce it was applied a verification list based on RDC 216/2004, as well as microbiological analyses (Thermotolerant coliforms and Salmonella sp.) on samples submitted to different treatments. The compliance rates on the evaluated blocks in the checklist were $96.3 \%$. The microbiological results showed no Salmonella sp. and the treatments with chlorine and lactic acid-based sanitizers showed compliance for coliforms. The use of the lactic acid-based sanitizer was as efficient as the chlorine-based sanitizer.
\end{abstract}

\section{Keywords:}

Microbiology. Sanitation. Vegetables.

Como você deve citar?

TEIXEIRA, Francisca Geane de Lima; ASSIS, Renata Carmo de; LEMOS, Lúcia Mara dos Reis. Análise comparativa da higienização da alface crespa (Lactuca sativa L.) utilizando sanitizante à base de ácido lático e à base de cloro. Cadernos UniFOA, Volta Redonda (RJ), v. 16, n. 46, p. 1-9, ago, 2021. 
Análise comparativa da higienização da alface crespa (Lactuca sativa L.) utilizando sanitizante à base de ácido lático e à base de cloro

\section{INTRODUÇÃO}

As hortaliças fornecem nutrientes a nossa dieta, tendo a função de proteger o homem de várias doenças, como a obesidade, o câncer, o acidente vascular cerebral e as doenças cardiovasculares. No entanto, esses alimentos podem servir de reservatório de microorganismos, como a Salmonella spp., a Escherichia coli patogênica e a Listeria monocytogenes, que podem causar surtos de doenças infecciosas (IWU; OKOH, 2019).

Existem muitas fontes possíveis de contaminação de produtos frescos devido à exposição e manuseio em diferentes ambientes. A utilização de múltiplos sistemas de desinfecção em toda cadeia produtiva é uma estratégia para as diferentes categorias de agentes patogênicos, com a finalidade de se prevenir a transmissão bacteriana e se beneficiar a saúde humana (LUNA-GUEVARA et al., 2019).

Entre as hortaliças mais vendidas para o consumo in natura está a alface (Lactuca sativa L.), bastante utilizada no preparo de sanduíches, saladas, decoração de pratos, etc. (SANTOS, 2012). 0 uso de rastreamento da matéria-prima, através da rotulagem da alface na região de cultivo e a data de colheita são recomendações da Food and Drug Administration (FDA), pois a análise mais eficaz desse rastreio protege os consumidores em caso de futuros surtos (CARSTENS et al., 2019).

A lavagem das hortaliças é a prática mais comum para se obter um produto com boa qualidade. A eficiência da operação de lavagem, entretanto, pode ser aumentada com a inclusão de antimicrobianos ou desinfetantes (FDA, 2006; Ll et al., 2020).

Juntamente com as etapas de lavagem e sanitização das hortaliças, é importante notar que outros fatores também podem afetar a segurança dos alimentos durante a preparação de saladas. Tais fatores incluem o conhecimento sobre segurança alimentar dos manipuladores de alimentos, a contaminação cruzada e a higiene de superfícies de contato com alimentos (SSEMANDA et al., 2018).

Nos últimos 30 anos, foram testadas outras soluções técnicas de higienização para aumentar o prazo de validade e a qualidade das hortaliças, entretanto o cloro continua a ser utilizado como principal agente desinfectante, sendo o mais comum devido a sua relação custo-eficácia, de fácil disponibilidade no mercado e de simples utilização. Muitas alternativas foram descobertas, tais como o dióxido de cloro, o ozônio, o peróxido de hidrogénio, as soluções à base de cálcio, os ácidos orgânicos, os antioxidantes, os compostos fenólicos, o óleo essencial, a água eletrolítica, o aquecimento, a irradiação, o ultrassom de alta potência, a luz pulsada e o plasma de gás frio (CORATO, 2020).

Os ácidos orgânicos devem receber maior atenção como alvo de pesquisas e estudos que busquem evidências para adequá-los como alternativa natural e eficaz para o controle microbiano de alimentos consumidos in natura ou minimamente processados, devendo-se levar em consideração a sua natureza, concentração e tempo de tratamento, pois esses fatores definirão a eficácia e a efetividade de diferentes ácidos orgânicos utilizados (CAVALCANTE; ASSIS, 2020).

Diante disso, a utilização de sanitizante comercial à base de ácido lático tem se tornado uma opção viável e uma alternativa ao cloro, por apresentar, em sua rotulagem, informações sobre como os microrganismos patogênicos são eliminados e como os alimentos são higienizados com economia de água e tempo, além de preservar as características naturais dos vegetais (ECOLAB, 2018).

Desse modo, o objetivo deste estudo foi avaliar as condições higiênico-sanitárias do processamento da alface crespa (Lactuca sativa L.) submetida ao tratamento com sanitizante à base de cloro e à base de ácido lático, em uma cozinha industrial no estado do Ceará. 


\section{METODOLOGIA}

\subsection{Delineamento do estudo e amostragem}

Trata-se de uma pesquisa analítica que foi realizada em uma cozinha industrial no Ceará, em 2019. Foram realizadas 16 visitas para aplicação de uma lista de verificação, contendo 27 itens, adaptada, baseada na Resolução de Diretoria Colegiada - RDC n²16/2004, que dispõe sobre o regulamento técnico de boas práticas em serviço de alimentação (BRASIL, 2004).

\subsection{Lista de verificação}

Os itens abordados no check list foram divididos por blocos, dentre eles: 1. Manipuladores; 2. Preparo dos vegetais; 3 . Higienização dos vegetais; 4. Recepção das hortaliças; 5 . Armazenamento das hortaliças. Após análise, os dados obtidos foram classificados como: grupo ótimo (76 a 100\% de atendimentos dos itens); grupo bom (51 a $75 \%$ de atendimento dos itens) e grupo ruim ( 0 a $50 \%$ dos itens) (BRASIL, 2004).

\subsection{Processamento da alface}

Após a recepção e armazenamento da matéria-prima, as alfaces passaram por uma seleção, na qual foram descartadas as folhas que apresentaram danos; posteriormente, receberam cortes no talo e o desfolhamento de forma manual, com o auxílio de facas inoxidáveis de lâmina fina. A primeira lavagem foi realizada com água corrente das folhas em tanques de aço inoxidável.

Na segunda seleção, foram retiradas as folhas com danos que não foram detectadas na seleção anterior. A segunda lavagem foi realizada em bandejas de aço inoxidável e teve por finalidade remover o fluido celular e vascular presente nas extremidades cortadas das tiras de folhas, sendo estes ricos em nutrientes e que auxiliam a multiplicação da carga microbiana inicial.

Foram aplicados três tratamentos nas alfaces, denominados tratamento-controle, que é o (T0), no qual consiste o tratamentos sem uso de agente sanitizante, realizado apenas uma limpeza em água corrente; o segundo tratamento é o (T1), com o uso de sanitizante à base de cloro; e, por último, o tratamento (T2) em que foi o usado o sanitizante à base de ácido lático.

Aproximadamente, $2 \mathrm{~kg}$ das alfaces foram divididos em lotes correspondentes aos três tratamentos (T0, T1 e T2) para realização dos processos em triplicata. A amostra-controle (T0) foi submetida às operações de seleção e lavagem com água corrente para a remoção de sujidades visíveis.

Para o tratamento das alfaces com uso da solução de cloro (T1), a hortaliça foi submetida sequencialmente à lavagem com detergente Bioverispol@ a 0,26\%, conforme a concentração do produto, seguida de enxague em água corrente. Posteriormente, as alfaces foram imersas em água clorada a 200 ppm de cloro por 10 minutos, em uma proporção de $200 \mathrm{~g}$ de cloro a 10 \%, em 100 litros de água, seguido de enxágue em água corrente.

Outra parte das hortaliças foi submetida à etapa de sanitização, com imersão no sanitizante à base de ácido lático (T2). Após a realização de seleção, lavagem e corte, a alface foi lavada com detergente Bioverispo ${ }^{\circledR}(0,26 \%)$, seguido de enxague em água corrente. Após esse procedimento, foi imerso ao sanitizante comercial à base de ácido lático, denominado de AFVT (Antimicrobial Fruit and Vegetable Treatment ${ }^{\circledR}$, na concentração de $0,26 \%$, em 100 litros de água, conforme recomendação do fabricante, 
por 90 segundos, sendo essa ação mecânica realizada com uso de bombeamento em um tanque de imersão, obtendo-se a alface sanitizada, não havendo necessidade de enxague.

Após o processo de higienização e sanitização de cada tratamento, foram coletadas $250 \mathrm{~g}$ de cada amostra e acondicionadas em sacos de polietileno à temperatura de $2^{\circ} \mathrm{C}$ a $5^{\circ} \mathrm{C}$ em câmara fria, por período de, no máximo, 6 horas.

\subsection{Análises Microbiológicas}

Não foram realizadas análises microbiológicas nas amostras antes de serem submetidas aos tratamentos com sanizantes. Por esse motivo, o nível de contaminantes na amostra era desconhecido. Em todos os tratamentos (T0, T1 e T2), foram avaliados os parâmetros microbiológicos de Coliformes termotolerantes a $45^{\circ} \mathrm{C}$ e presença/ausência de Salmonella sp.

Os parâmetros analisados seguiram recomendação para padrão microbiológico em frutas e vegetais, estabelecidos pela RDC n 12/2001, da Agência Nacional de Vigilância Sanitária (ANVISA) (BRASIL, 2001). Para pesquisa de Salmonella sp., os resultados foram expressos em ausência/presença desse microrganismo em $25 \mathrm{~g}$ de amostra. A Contagem de coliformes termotolerantes a $45^{\circ} \mathrm{C}$ foi realizada através da técnica de tubos múltiplos de diluições seriadas e os resultados foram expressos em Número mais Provável (NMP/mL), seguindo-se a metodologia APHA (2001). As análises foram realizadas em um laboratório técnico particular no município de Fortaleza - CE.

Comitê de Ética e Pesquisa

Por questões éticas e para se evitar qualquer tipo de constrangimento aos manipuladores de alimentos, o processamento e a coleta de dados foram realizados após a aprovação da pesquisa, Gestão da Qualidade Total, em uma Unidade de Alimentação e Nutrição transportada de grande porte, no estado do Ceará, pelo Comitê de Ética em Pesquisa da Universidade Estadual do Ceará, segundo parecer 05770918.3.0000.5534, respeitando-se a Resolução 466/12, do Conselho Nacional de Saúde (CNS). Análise estatística

Os dados coletados foram tabulados com auxílio do Microsoft Excel 2016 e expressos através de gráfico. As análises microbiológicas serão apresentadas em forma de tabela.

\section{RESULTADOS E DISCUSSÃO}

\subsection{Lista de Verificação}

Durante o processamento das alfaces, foi possível verificar que quatro blocos avaliados na lista de verificação apresentaram $100 \%$ de índices de conformidades; já o bloco armazenamento dos vegetais, apresentou $80 \%$ de conformidade (Figura 1).

Ao se avaliar os 27 itens, o processamento dos vegetais apresentou percentual de $96,30 \%$ de conformidade, o qual se enquadra na classificação grupo ótimo (76 a 100\% de atendimento dos itens). 
Figura 1 - Percentual de itens em conformidade e não conformidade durante o preparo das saladas, de acordo com a lista de verificação (check-list) em uma cozinha industrial. Fortaleza - CE, 2019

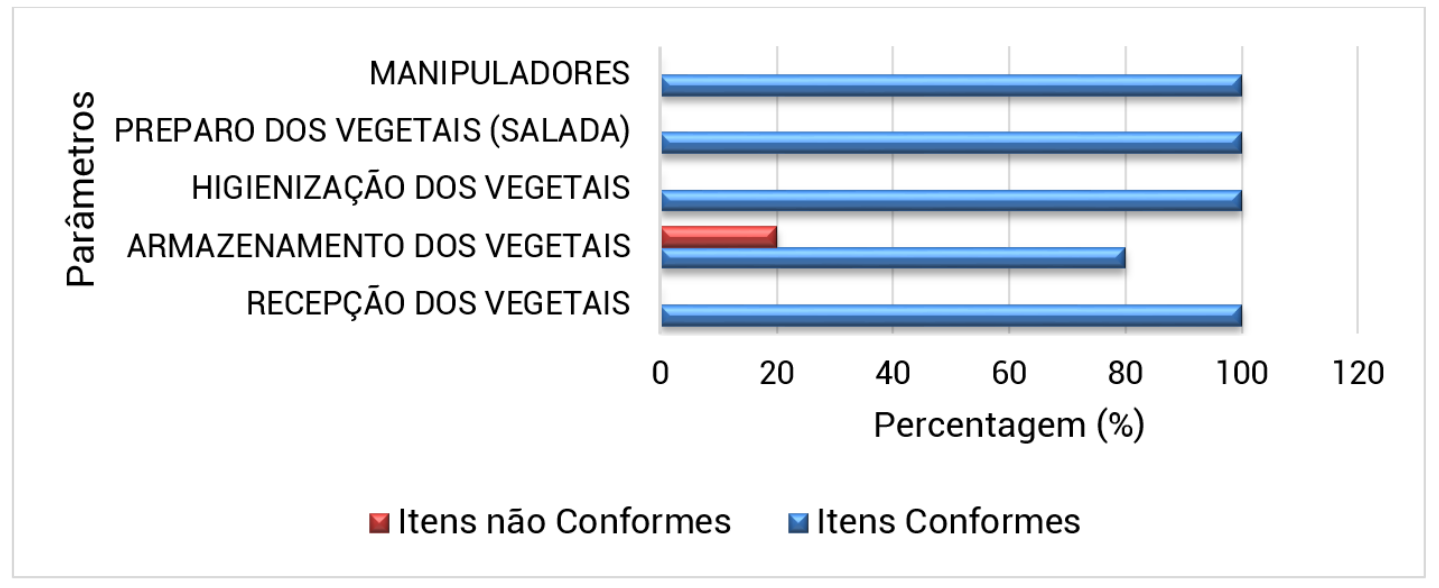

Fonte: Dos autores, 2019

As saladas cruas são um grupo de alimentos que podem apresentar as maiores contagens microbiológicas para os indicadores de higiene e também para os patógenos de origem alimentar (Estafilococos aureus e Escherichia coli), o que aponta para maus procedimentos de desinfecção, contaminação cruzada e ausência de processamentos térmicos (SOARES et al., 2020). Como colocado por Manhique, (2016), ao avaliar as condições higiênicas-sanitárias e contaminação microbiológica em alimentos e manipuladores de 110 manipuladores, foi realizado swab de mãos em 55 , em que se apresentou elevado índice de contaminação por Enterobacteriaceae.

Com relação às boas práticas de higiene pessoal, nas visitas realizadas, os manipuladores apresentaram uniformes limpos de cor clara, cabelos sempre presos por touca e gorro, ausência de adornos, barba, unhas sem esmaltes ou feridas. Foi observado que os manipuladores, ao saírem e ao entrarem no setor, sempre higienizavam as mãos, conforme procedimentos adotados pela RDC 216/2004 (BRASIL, 2004).

Oliveira et al. (2008), ao analisarem cozinhas em creches no Município de São Paulo, observaram a presença de manipuladores com adornos e unhas compridas, o que difere do presente estudo. Existe um consenso de que são necessários treinamento para os manipuladores de alimento, a fim de se evitar e controlar as doenças de origem alimentar. Dessa forma, esses profissionais devem ter formação eficaz e de qualidade, assegurada de forma rotineira (TUNCER; AKOĞLU, 2020).

Sobre esse assunto, Oliveira (2020) aponta que unhas compridas representam $31 \%$ das ocorrências de não conformidades. 0 autor enfatiza sobre a importância dos manipuladores apresentarem unhas curtas e sem esmaltes, para que haja uma correta higienização das mãos, pois as unhas retêm grande número de microrganismos como, por exemplo, os patógenos.

Em complementação ao exposto, registra-se que as atitudes e práticas autorreferidas de manipularoes tiveram uma baixa concordância com observações realizadas em um estudo. E, embora $100 \%$ dos manipuladores da empresa analisada considerarem que o armazenamento inadequado de alimentos possa representar um risco à saúde de quem os consome, foi perceptível um nível insatisfatório de conhecimento, atitudes e práticas sobre conceitos essenciais de segurança alimentar (AUAD et al., 2019).

Pereira et al. (2013) apontaram algumas falhas durante a preparação de saladas de alface fresca, originárias das condições de transporte, armazenamento e limpeza, explicando aos operadores de ali- 
Análise comparativa da higienização da alface crespa (Lactuca sativa L.) utilizando sanitizante à base de ácido lático e à base de cloro

mentos que a lavagem e sanitização possuem passos a serem seguidos de forma correta e que todas essas etapas são de grande importância para garantir a segurança alimentar dos produtos.

Cararo e Hauteive (2013) avaliaram a higienização de móveis e utensílios e a qualidade e apresentação de saladas servidas em uma rede de supermercados. Os resultados quanto à qualidade higiênico-sanitária apresentaram que o supermercado A demonstra $60 \%$ de não conformidade na higienização dos utensílios, móveis e manipuladores, e $40 \%$ de conformidade, enquanto o supermercado $B$ apresenta $60 \%$ de conformidade e $40 \%$ de não conformidade. Em relação à higienização das saladas, 0 supermercado $A$ apresentou $100 \%$ de não conformidade, enquanto o supermercado B apresentou $100 \%$ de não conformidade. Os autores concluíram que supermercado A não realizavam de forma adequada a desinfecção das hortaliças. Como método de avaliação, foi aplicado lista de verificação.

\subsection{Análises microbiológicas}

Os resultados obtidos nas análises microbiológicas (Tabela 1) mostram que o tratamento-controle (T0) apresentou o limite excedido pela legislação para coliformes termotolerantes, o que era de se esperar, pois fazer uso apenas de água corrente para eliminação de microorganismos não é eficiente.

Independente do nível de contaminação existente anteriormente, os tratamentos com sanitização por cloro (T1) e com sanitizantes à base de ácido lático apresentaram conformidades, segundo a legislação brasileira vigente, preconizada pela RDC nº 12/2001 (BRASIL, 2001).

Tabela 1 - Resultados das análises microbiológicas correspondente aos tratamentos T0, T1 e T2 na alface (Lactua Sanitva L.) utilizados para saladas em uma cozinha industrial, Fortaleza- CE, 2019.

\begin{tabular}{ccccc}
\hline Tratamento & $\begin{array}{c}\text { Coliformes } \\
\text { termotolerantes (NMP/ } \\
\mathbf{m L})\end{array}$ & Legislação* $(\mathrm{NMP} / \mathbf{m L})$ & Salmonella sp** $^{\star}$ & Legislação** $^{*}$ \\
\hline $\mathrm{T} 0$ & 150 & $5 \times 10^{2}$ & Ausência & Ausência \\
\hline $\mathrm{T} 1$ & $<4,0$ & $5 \times 10^{2}$ & Ausência & Ausência \\
\hline $\mathrm{T} 2$ & $<3,0$ & $5 \times 10^{2}$ & Ausência & Ausência \\
\hline
\end{tabular}

Legenda: T0 (Tratamento sem o uso de sanitização); T1 (Tratamento com sanitizante à base de cloro); T2 (Tratamento com sanitizante a base de ácido lático). (*) Valor Máximo Permitido para coliformes termotolerantes (BRASIL, 2001);

(**) Ausência/Presença de Salmonella em $25 \mathrm{~g}$ de amostras (BRASIL, 2001). NMP/mL: Número mais provável. Fonte: Dos autores, 2019.

A literatura relata estudos de análise microbiológicas em folhosos, como reportado por Duque et al. (2014), ao analisarem 48 amostras de alface coletadas em dois supermercados e em feiras livres em Vitória da Conquista - BA. Das amostras analisadas, todas apresentaram contaminação por parasitas.

Mallet et al. (2017) verificaram que $33 \%$ das amostras de saladas analisadas encontravam-se fora dos limites preconizados, não estando aptas à comercialização e, consequentemente, ao consumo humano. Resultados semelhantes a essa pesquisa foram encontrados Zanoni e Gelink. (2013), ao analisarem salada crua em três restaurantes em Santa Catarina, que apresentou ausência para Salmonella sp., porém com altos índices de Coliformes termotolerantes.

O nível de contaminação por enteroparasitas, tais como, helmintos e protozoários patogênicos, por artrópodes inteiros e/ou partes delas em hortifrútis são frequentes, muitas vezes, tanto em agro-indústrias, como em hipermercados. No entanto, observa-se, em estudo, que existe uma correlação 
positiva entre as boas práticas adaptadas em matéria de higiene nesses produtos com uma menor taxa de contaminação correspondente a uma melhor confiabilidade do produto (MALDONADE et al., 2019).

Em relação aos agentes sanitizantes para a redução dos microrganismos presentes, Huang e Chen (2011), ao analisarem os efeitos de ácidos orgânicos, peróxido de hidrogênio e calor suave em espinafre, constataram que o ácido lático em $1 \%$ mostrou-se ser a mais efetiva solução de tratamento, com redução de $1,9 \log$ de UFC/g.

Amrutha et al. (2017), em sua pesquisa, avaliaram a capacidade de três ácidos orgânicos (cítrico, acético e lático) e o ácido lático foi eficaz na inativação de Escherichia coli e Salmonella. Os autores concluíram que os ácidos orgânicos podem atuar como possíveis sanitizantes, sendo efetivos na redução da carga microbiana associada a frutas e vegetais frescos.

Santos et al. (2012), em sua pesquisa, ao avaliarem a eficiência do cloro na sanitização das alfaces (Lactuca sativa L.), concluíram que a utilização de água sanitária a 200 ppm de cloro ativo reduziu a carga microbiana inicial de bactérias heterotróficas mesófilas e coliformes termotolerantes presentes em folhas da alface. Esse resultado corrobora as análises microbiológicas realizadas nesta pesquisa, já que a desinfecção da alface por sanitizante à base de cloro também foi efetiva.

É imprescindível o correto manuseio e higienização desses alimentos, para se evitar a possível contaminação de seus consumidores e consequentes surtos, pois a presença ou ausência desses microorganismos são diretamente proporcional às boas práticas de fabricação constantes e permanentes na área de produção de alimentos (BIERHAS et al., 2019).

\section{CONCLUSÃO}

O uso do sanitizante à base de cloro e à base de ácido lático mostraram-se eficientes nos controles microbiológicos nas amostras de alface analisadas, reduzindo significativamente a microbiota em relação ao tratamento-controle (TO).

Dessa forma, foi possível concluir que os resultados obtidos asseguraram um produto de qualidade e a lista de verificação apresentou grandes percentuais de conformidade, sugerindo que o processamento das alfaces para saladas está sendo realizado de forma segura, visando à segurança alimentar para os consumidores.

Entretanto, são necessários mais estudos sobre a eficiência do sanitizante à base de ácido lático em outros vegetais, visto que a amostragem foi pequena.

\section{REFERÊNCIAS}

AMRUTHA, B.; SUNDER, K.; SHETTY. P. H. Effect of organic acids on biofilm formation and quorum signaling of pathogens from fresh fruits and vegetables, Microbial Pathogenesis, v. 111, p. 156-162, 2017.

APHA: American Public Health Association. Standard methods for the examination of water and wastewater. 17. ed. Washington: APHA, 2001. 
Análise comparativa da higienização da alface crespa (Lactuca sativa L.) utilizando sanitizante à base de ácido lático e à base de cloro

AUAD, L. I.; GINANI, V. C.; STEDEFELDT, E.; NAKANO, E. Y.; NUNES, A. C. S.; ZANDONADI, R. P. Food Safety Knowledge, Attitudes, and Practices of Brazilian Food Truck Food Handlers. Nutrients, v.11, n.8, p.1-19, 2019.

BRASIL. Ministério da Saúde. Secretaria de Vigilância Sanitária. Resolução - RDC n. 12, de 02 de janeiro de 2001. Regulamento técnico sobre padrões microbiológicos para alimentos. Diário Oficial da União, Brasília, 10 de janeiro de 2001. Disponível em: http://bvsms.saude.gov.br/bvs/saudelegis/anvisa/2001/ res0012_02_01_2001.html. Acesso em: 04 abr. 2018.

BRASIL. Ministério da Saúde. Agência Nacional de Vigilância Sanitária. Resolução-RDC nº . 216, de 15 de setembro de 2004. Dispõe sobre o Regulamento Técnico de Boas práticas para serviços de alimentação. Diário Oficial (da) República Federativa do Brasil, Brasília, DF, 2004. Portaria 31/05 Lista de verificação das boas práticas em serviço de alimentação. Disponível em: http://portal.anvisa.gov.br/documents/33916/388704/ RESOLU\%25C3\%2587\%25C3\%25830- RDC\%2BN\%2B216\%2BDE\%2B15\%2BDE\%2BSETEMBRO\%2BDE\% 2B2004. pdf/23701496-925d-4d4d-99aa-9d479b316c4b\#: :text=RESOLU\%C3\%8 7\%C3\%830\%2DRDC\%20 N\%C2\%B0\%20216,que\%20lhe\%20confere\%20o\%20art. Acesso em: 04 abr. 2018.

BIERHAS, C. C.; MACHADO, A. B.; PICOLI, S. U.; OSORIO, D. M. M.; BERLESE, D. B. Physical-chemical and microbiological analysis of water of irrigation and microbiological analysis of lettuce (Lactuca sativa) in the Municipality of Ivoti/RS. Ci. e Nat., v.41, n.e55, p.1-9, 2019.

CARARO, N.; HAUTRIVE, T. P.; Quality salads served on a network of rotisseria supermarkets. Revista Brasileira de Tecnologia Agroindustrial. v.7, n.1, p.943-954, 2013.

CARSTENS, C. K., SALAZAR, J. K., \& DARKOH, C. Multistate Outbreaks of Foodborne Illness in the United States Associated With Fresh Produce From 2010 to 2017. Frontiers in Microbiology. 2019.

CAVALCANTE, R.R.; ASSIS, R.C. Utilization of organic acids as an alternative for food hygienization: an integrating review. Holos Environment, v.20, n.3, p.335-351, 2020.

CORATO, U.D. Improving the shelf-life and quality of fresh and minimally-processed fruits and vegetables for a modern food industry: A comprehensive critical review from the traditional technologies into the most promising advancements. Journal Critical Reviews in Food Science and Nutrition, v.60, n.6, p.2020.

DUQUE, L; VIEIRA, F; DAMÁSIO, A. Pesquisa de ovos de helmintos e oocitos de protozoários em alfaces (Lactuca Satura) comercialização em feiras-livres e supermercados. Revista Veterinária em foco, v.11, n. 2, 2014.

ECOLAB. Segurança de alimentos descomplicada. Disponível em: https://pt-br.ecolab.com/stories/ food-safety-made-easy. Acesso em: 04 abr. - 2018.

FDA, 2006. Commodity Specific Food Safety Guidelines for the Lettuce and Leafy Greens Supply Chain, 1st edition. Disponível em: https://www.fda.gov/media/77279/download. Acesso em: 15 jun. 2020.

HUANG, Y; CHEN, H. Effect of organic acids, hydrogen peroxide and mild heat on inactivation of Escherichia coli 0157:H7 on baby spinach. Food Control. v.22, p.1178-1183, 2011.

IWU, C. D.; OKOH, A. I. Preharvest Transmission Routes of Fresh Produce Associated Bacterial Pathogens with Outbreak Potentials: A Review. International Journal of Environmental Research and Public Health, v.16, n.22, p.4407, 2019. 
LI, K.W; ETIENNE, X.; CHIU, Y.; JONES, L.; KHOURYIEH, H.; JIANG, W.; SHEN, C. Validation of triple-wash procedure with a $\mathrm{H} 2 \mathrm{O} 2$-peroxyacetic acid mixer to improve microbial safety and quality of butternut squashes and economic feasibility analysis. Food Control, v.112, 2020.

LUNA-GUEVARA, J. J.; ARENAS-HERNANDEZ, M. M. P.; MARTÍNEZ DE LA PEÑA, C.; SILVA, J. L.; LUNAGUEVARA, M. L. The Role of Pathogenic E. coli in Fresh Vegetables: Behavior, Contamination Factors, and Preventive Measures. International Journal of Microbiology, p.1-10, 2019.

MALDONADE, I. R.; GINANI, V. C.; RIQUETTE, R. F. R.; GURGEL-GONÇALVES, R.; MENDES, V. S.; MACHADO, E. R. Good manufacturing practices of minimally processed vegetables reduce contamination with pathogenic microorganisms. Rev Inst Med Trop. v.61, n.e14, p.1-9, 2019.

MALLET, A. C. T.; ROCHA, K. S.; OLIVEIRA, C. F.; SARON, M. L. G.; SOUZA, E. B. Avaliação microbiológica de saladas cruas servidas em restaurantes do tipo self-service do município de Volta Redonda (RJ). Cadernos UniFOA, v.34, p.89-96, 2017.

OLIVEIRA, M. N.; BRASIL; A. L. D.; TADDEI, J. A. C. Avaliação das condições higiênicas sanitárias das cozinhas de creches públicas e filantrópicas. Ciências e saúde coletiva, v.13, n.3, p.1051- 1060, 2008.

PEREIRA E. L; RODRIGUES A; RAMALHOSA E. Influence of working conditions and practices on fresh-cut lettuce salads quality. Food Control, v.33, p.406-412, 2013.

SANTOS, H. S.; MURATORI, M. C. S.; MARQUES, A. L. A.; ALVES, V. C.; CARDOSO FILHO, F. C.; COSTA, A. P. R. Avaliação da eficácia da água sanitária na sanitização de alfaces (Lactuca sativa L.). Revista Instituto Adolfo Lutz, v.71, n.1, p.56-60, 2012.

SOARES, K.; MOURA, A.T.; GARCÍA-DÍEZ, J. et al. Evaluation of Hygienic Quality of Food Served in Universities Canteens of Northem Portugal. Indian J Microbiol, v.60, p.107-114, 2020.

SSEMANDA, J. N.; JOOSTEN, H.; BAGABE. M. C.; ZWIETERING, M. H.; W. REIJ, M. W. Reduction of microbial counts during kitchen scale washing and sanitization of salad vegetables. Food Control, v.85, p.495-503, 2018.

TUNCER, A.; AKOĞLU, A. Food safety knowledge of food handlers working in hotel kitchens in Turkey. Food and Health, v.6, n.2, p.77-89, 2020. 